\title{
Postprandial lipid metabolism and thrombosis
}

\author{
BY G. J. MILLER
}

MRC Epidemiology and Medical Care Unit, Wolfson Institute of Preventive Medicine, St Bartholomew's and the Royal London School of Medicine and Dentistry, Charterhouse Square, London ECIM 6BQ

The atherosclerotic basis of CHD and the pathogenic roles in this condition played by disturbances of lipoprotein metabolism, high blood pressure and cigarette smoking are well known (Grundy et al. 1987). In addition, the major cause of sudden cardiac death (Davies \& Thomas, 1984), acute myocardial infarction (De Wood et al. 1980), unstable angina pectoris (Fuster \& Chesebro, 1986) and silent myocardial ischaemia (Gurfinkel et al. 1994) is recognized to be the formation of thrombus at sites where the endothelium overlying atheromatous plaques has sloughed or fissured (Davies, 1996). The resultant contact of circulating blood with atheromatous material permits the formation of complexes of the plasma protein factor VII with its co-factor, tissue factor, present in abundance in the core of the plaque (Wilcox et al. 1989). These complexes are powerfully pro-coagulant, and their rapid formation in high local concentration overwhelms the inhibitory mechanisms which normally maintain the coagulant pathway at a basal level of activity (Bauer \& Rosenberg, 1987). An amplifying cascade of linked proteolytic reactions is triggered, culminating in the generation of thrombin in sufficient quantity to produce the haemostatic mass of fibrin and aggregated platelets which is the thrombus (Macfarlane, 1964).

Factor VII exists in plasma mainly as a single-chain zymogen (FVII) but also in trace quantity as the derivative two-chain enzyme, activated factor VII (FVIIa; Wildgoose et al. 1992; Morrissey et al. 1993). It is the FVIIa-tissue factor complex that is responsible for the initiation of coagulation and, a priori, the magnitude of the thrombotic response to plaque disruption is likely to depend in part on the concentration of circulating FVIIa at that instant. This is the rationale of warfarin anticoagulant therapy which is known to reduce the risk of thrombosis in CHD (International Anticoagulant Review Group, 1970; Chalmers et al. 1977). Warfarin acts by suppressing the activity level of factor VII and other vitamin K-dependent clotting factors. On this account, the discovery of a high factor VII coagulant activity (FVIIc) in men at high risk for fatal CHD is of particular relevance (Heinrich et al. 1994; Ruddock \& Meade, 1994). Plasma FVIIc is a function of the concentrations of FVIIa and FVII (Miller et al. 1994), and the question immediately arises as to the causes of an elevated factor VII, months or even years before the onset of an acute coronary event.

\section{POSTPRANDIAL LIPAEMIA AND FACTOR VII}

The consistent epidemiological and clinical associations between hypertriacylglycerolaemia and an increased FVIIc (Constantino et al. 1977; Fuller et al. 1979; Stirling et al. 1984; Miller et al. 1985; Bruckert et al. 1989; Mitropoulos et al. 1989), coupled with early evidence for a reduction in FVIIc with successful treatment of hypertriacylglycerolaemia (Elkeles et al. 1980; Simpson et al. 1983), led to an examination of the effects on factor VII of the manipulation of plasma triacylglycerol concentration by dietary means.

In an earlier study, six healthy adults consumed two experimental diets in random order, one containing about $13 \%$ of energy as fat and taken for 2 weeks, the other containing $62 \%$ of energy as fat and taken for 3 weeks (Miller et al. 1986). Fasting blood 
Table 1. Blood lipids and clotting factors during two dietary regimens (From Miller et al. 1986)

\begin{tabular}{|c|c|c|c|c|c|}
\hline & \multirow[t]{2}{*}{ Low-fat } & \multirow[t]{2}{*}{ High-fat } & \multicolumn{2}{|c|}{$\begin{array}{c}\text { Difference } \\
\text { between regimens }\end{array}$} & \multirow{2}{*}{$\begin{array}{l}\text { Statistical significance } \\
\text { of difference: } \\
P\end{array}$} \\
\hline & & & Mean & SE & \\
\hline Energy $(\mathrm{kJ} / \mathrm{d})$ & 9339 & 11959 & 2619 & 578 & $<0.01$ \\
\hline Fat (\% energy) & $12 \cdot 8$ & $62 \cdot 1$ & & & \\
\hline Serum cholesterol (mmol/l) & $4 \cdot 24$ & 4.70 & 0.46 & $0-18$ & 0.05 \\
\hline Serum fasting triacylglycerol $(\mathrm{mmol} / \mathrm{l})$ & 1.21 & 0.83 & -0.38 & 0.12 & 0.03 \\
\hline Factor VII coagulant activity (\% standard) & 81.7 & 97.5 & 15.8 & 4.8 & $0 \cdot 02$ \\
\hline Prothrombin (\% standard) & 96.4 & $96 \cdot 2$ & -0.2 & 0.8 & NS \\
\hline Factor X (\% standard) & 88.7 & $86 \cdot 7$ & -0.2 & $2 \cdot 1$ & NS \\
\hline Fibrinogen $(\mathrm{g} / \mathrm{l})$ & $3 \cdot 1$ & 3.0 & 0.1 & 0.2 & NS \\
\hline
\end{tabular}

samples were taken before breakfast at 2 or $3 \mathrm{~d}$ intervals, and assayed for FVIIc, prothrombin, factor $X$ activity, fibrinogen concentration and lipid concentrations. The mean averages of these results are presented in Table 1, showing that whereas fasting triacylglycerol concentration was higher during the low-fat regimen than in the high-fat period, FVIIc was lower on the low-fat diet. These results indicated that the positive relationship between FVIIc and triacylglycerol concentration in cross-sectional community studies was not due to any simple binding of factor VII to VLDL. Instead, FVIIc was significantly related to the fat content of the diet. Dietary energy intake was also increased during the high-fat regimen, although the excess was completely accounted for by fat. However, a second study (Miller et al. 1986; Table 2) showed that a $50 \%$ increase in dietary energy had no effect on FVIIc when provided as carbohydrate, but did have a significant effect when in the form of fat.

Equally importantly, fasting FVIIc immediately before breakfast was found to be positively correlated with the amount of fat consumed during the previous $24 \mathrm{~h}(r 0.52$, $P<0.01$ ), while the second study showed that this effect was discernible within $8 \mathrm{~h}$ of commencement of a fat-enriched diet (Table 2). Subsequent studies have demonstrated a postprandial elevation in FVIIc within $3 \mathrm{~h}$ of consumption of a fat-rich test meal (Miller $e t$ al. 1991).

Marckmann et al. (1993) gave four healthy male adults four isoenergetic diets of different fat $(20 \%$ or $50 \%$ of energy) and fibre ( 2 or $4 \mathrm{~g} / \mathrm{MJ})$ levels, each for $2 \mathrm{~d}$. The highfat diets were associated with much higher postprandial peak FVIIc levels than the low-fat

Table 2. The effects of dietary fat and carbohydrate enrichment on factor VII (From Miller et al. 1986)

\begin{tabular}{lccc}
\hline \hline & Usual diet & Fat-enriched diet & Carbohydrate-enriched diet \\
\hline Total energy (kJ) & 7222 & 10854 & 10925 \\
Fat (kJ) & 2377 & 5904 & 2473 \\
Carbohydrate (kJ) & 3594 & 3636 & 6958 \\
& & & 103 \\
Factor VII activity (\% standard): & 101 & $111^{*}$ & 99 \\
$\quad$ At 17.00 hours & 98 & $106^{*}$ & \\
In fasting sample following morning & & & \\
\hline \hline
\end{tabular}

Mean values were significantly different from those for usual diet (paired $t$ test): ${ }^{*} P=0.02$. 
diets, whereas fibre content had no effect on FVIIc whatsoever. These subjects, aged 21-30 years, cleared a fat load very efficiently, such that the postprandial and $24 \mathrm{~h}$ mean triacylglycerol concentrations were not significantly influenced by the dietary fat intake. The investigators, therefore, concluded that the magnitude of the postprandial increase in FVIIc was probably determined primarily by the mass of dietary triacylglycerol transported in chylomicrons and VLDL rather than the postprandial change in triacylglycerol concentration. Marckmann et al. (1993) also estimated the levels of FVIIa using a variant of the factor VII bioassay (employing bovine tissue factor rather than human tissue factor) and FVII as factor VII antigen (FVIIag) by ELISA. They demonstrated that the postprandial increase in FVIIc was due entirely to activation of factor VII with a rise in FVIIa. This result was subsequently confirmed in a larger study (Bladbjerg et al. 1994), and accorded with the findings of Miller $e t$ al. (1991).

Silveira et al. (1994) followed the postprandial responses to a standard test meal (containing olive oil, $50 \mathrm{~g} / \mathrm{m}^{2}$ body surface area) in thirty-three patients who had survived a myocardial infarction and ten healthy controls, the mean ages of both groups being 49 years. Substantial activation of factor VII was observed within $3 \mathrm{~h}$ of the oral fat load, but unlike in the younger subjects of Marckmann et al. (1993), peak factor VII activation was positively associated with rise in plasma triacylglycerol concentration. Hypertriacylglycerolaemic patients were found to have lower levels of fasting and postprandial FVIIa than the healthy controls, despite their higher triacylglycerol concentrations. Together, the findings of Marckmann et al. (1993) and Silveira et al. (1994) can be reconciled if factor VII activation is determined both by the rate of lipolysis of triacylglycerol and the rate at which the products of lipolysis are cleared from the circulation.

The importance of lipoprotein lipase (EC 3.1.1.34; LPL) activity for factor VII is emphasized by a study of familial complete LPL deficiency (Mitropoulos et al. 1992). Despite their massive hypertriacylglycerolaemia, both FVIIc and FVIIag were normal in patients with this condition. How the magnitude of lipolysis and turnover of remnant particles might influence factor VII is not fully understood, but one possible explanation relates to the creation of a negatively-charged surface on triacylglycerol-rich lipoproteins which then activates the contact system of coagulation. Activation of this system depends on the interactions of factor XII, prekallikrein and high-molecular-mass kininogen with a suitable surface, on which factor XII is converted to the enzyme factor XIIa and prekallikrein is converted to kallikrein. Triacylglycerol-rich lipoproteins will provide such a surface when treated with LPL (Mitropoulos et al. 1992; McNally et al. 1996). The products of contact activation initiate a series of linked reactions involving factor XI, which lead to the activation of factor IX. Both activated factor XII and activated factor IX will convert FVII to FVIIa. This concept is supported by in vitro experiments which have demonstrated activation of factor VII following incubation of whole plasma with lipoprotein remnants produced by pre-incubation of VLDL with LPL (Mitropoulos et al. 1993). However, studies in patients with inherited deficiencies of clotting factors indicate that the previously described sequence of events cannot account entirely for the postprandial responses of FVIIc (Miller $e t$ al. 1996). Patients with complete deficiency of either factor XII or factor XI show a normal postprandial response of factor VII to fatty meals, thus excluding obligatory roles for these clotting factors in the process. However, patients with complete factor IX deficiency fail to show any change in FVIIc or FVIIa after a fat-rich meal, although a normal response is restored following factor IX-replacement therapy. Speculatively, perhaps a contact surface on triacylglycerol-rich particles and their remnants also leads to activation of factor IX and, hence, factor VII by pathways not involving factor XII and factor XI. 


\section{POSTPRANDIAL FACTOR VII AND DIETARY FAT COMPOSITION}

Activation of factor VII during alimentary lipaemia takes place whatever the fatty acid composition of the meal. In an early study (Miller et al. 1991), nine healthy adults consumed two diets of standardized energy and total fat content in random order, each for $7 \mathrm{~d}$. In one diet polyunsaturated : saturated fatty acids $(\mathrm{P}: \mathrm{S})$ was less than $0 \cdot 3$, and in the other greater than 3.0. No difference in FVIIc or FVIIag was observed on the final days of the two regimens, either fasting or postprandially. Salomaa et al. (1993) gave ten middleaged men two isoenergetic test meals each containing $1 \mathrm{~g}$ fat $/ \mathrm{kg}$ body weight. In one meal the fat was supplied as cream and in the other as sunflower oil. Similar increases in FVIIc were observed after the two meals. T. De Grassi, T. A. B. Sanders and G. J. Miller (unpublished results) observed the effects of five different test meals of standardized energy, total fat, protein and fibre content on postprandial lipaemia and factor VII in sixteen adults. The meals were rich respectively in fatty acids $16: 0,18: 0,18: 1 n-9$ cis, 18:1n-9 trans, and $8: 0+10: 0$. There was a striking positive relationship between the magnitude of the postprandial lipaemia and the peak level of FVIIc after the meal. The high-18: $1 n-9$ meal induced the greatest increases in plasma triacylglycerol concentration $(P<0.05$, compared with 18:0) and FVIIc, whereas the 8:0+10:0 meal induced no significant change in either variable from its fasting level. In seemingly excluding any appreciable effect of fatty acid composition per se on factor VII, these results supported those of Silveira et al. (1994) in emphasizing a relationship between peak factor VII activation and the increase in plasma triacylglycerol concentration postprandially. A similar dose-response relationship between the fat content of the test meal and the postprandial rise in FVIIa has been described by Sanders et al. (1996). The relationship is not invariant, however. When Yahia \& Sanders (1996) replaced $15 \mathrm{~g}$ olive oil with $15 \mathrm{~g}$ fish oil (MaxEPA; Seven Seas, Hull) in a $90 \mathrm{~g}$ olive oil test meal, a marked reduction in postprandial lipaemia occurred without any change in the postprandial increase in FVIIc.

\section{POSTPRANDIAL LIPAEMIA AND THROMBOSIS}

A circadian rhythm to acute myocardial infarction and sudden cardiac death is well recognized, with peak rates of onset in the early morning and (to a lesser extent) in the late afternoon (Gnecchi-Ruscone et al. 1994; Muller et al. 1994). The explanation for this rhythm is uncertain, but a concordant diurnal variation in risk factors that have a role in plaque disruption or the strength of the thrombotic response to this disruption is one possibility. The most striking feature of this diurnal variation in the onset of an acute coronary episode is the rapid climb from a nadir at about 02.00 hours to a peak incidence about $6 \mathrm{~h}$ later at 08.00 hours. Morning increases in heart rate, blood pressure, platelet aggregability and suppression of fibrinolytic activity have been proposed as possible factors, but to this list could be added activation of factor VII following a heavy meal the previous evening. As mentioned previously, the magnitude of the thrombotic response to plaque disruption is likely to depend in part on the concentration of circulating FVIIa at that instant. This concentration will depend on the time and fat content of the previous meal. Current dietary advice for the prevention of $\mathrm{CHD}$, which includes a reduction in the fat content of the diet, therefore, may benefit the patient not only by reducing plasma cholesterol levels but also by improving the coagulant status of the blood.

\section{REFERENCES}

Bauer, K. A. \& Rosenberg, R. D. (1987). The pathophysiology of the prethrombotic state in humans: insights gained from studies using markers of hemostatic system activation. Blood 70, 345-350. 
Bladbjerg, E. M., Marckmann, P., Sandstrom, B. \& Jespersen, J. (1994). Non-fasting factor VII coagulant activity (FVII:c) increased by high-fat diet. Thrombosis and Haemostasis 71, 755-758.

Bruckert, E., Carvalho de Sousa, J., Giral, P., Soria, C., Chapman, M. J., Caen, J. \& de Gennes, J.-L. (1989). Interrelationship of plasma triglyceride and coagulant factor VII levels in normotriglyceridemic hypercholesterolemia. Atherosclerosis 75, 129-134.

Chalmers, T. V., Matta, R. J., Smith, H. \& Kunzler, A.-M. (1977). Evidence favouring the use of anticoagulants in the hospital phase of acute myocardial infarction. New England Journal of Medicine 297, 1091-1096.

Constantino, M., Merskey, C., Kudzma, D. J. \& Zucker, M. B. (1977). Increased activity of vitamin Kdependent clotting factors in human hyperlipoproteinaemia-association with cholesterol and triglyceride levels. Thrombosis and Haemostasis 38, 465-474.

Davies, M. J. (1996). The contribution of thrombosis to the clinical expression of coronary atherosclerosis. Thrombosis Research 82, 1-32.

Davies, M. J. \& Thomas, A. (1984). Thrombosis and acute coronary-artery lesions in sudden cardiac ischemic death. New England Journal of Medicine 310, 1134-1140.

De Wood, M. A., Spores, J., Notske, R., Mouser, L. T., Burroughs, R., Golden, M. S. \& Lang, H. T. (1980). Prevalence of total coronary occlusion during the early hours of transmural myocardial infarction. New England Journal of Medicine 303, 897-902.

Elkeles, R. S., Chakrabarti, R., Vickers, M., Stirling, Y. \& Meade, T. W. (1980). Effect of treatment of hyperlipidaemia on haemostatic variables. British Medical Journal 281, 973-974.

Fuller, J. H., Keen, H., Jarrett, R. J., Omer, T. \& Meade, T. W. (1979). Haemostatic variables associated with diabetes and its complications. British Medical Journal 2, 964-966.

Fuster, V. \& Chesebro, J. H. (1986). Mechanism of unstable angina. New England Journal of Medicine 315, 1023-1025.

Gnecchi-Ruscone, T., Piccaluga, E., Guzzetti, S., Contini, M., Montano, N. \& Nicolis, E. on behalf of the GISSI2 Investigators (1994). Morning and Monday: critical periods for the onset of acute myocardial infarction. European Heart Journal 15, 882-887.

Grundy, S. M., Greenland, P., Herd, A., Huebsch, J. A., Jones, R. J., Mitchell, J. H. \& Schlant, R. C. (1987). Cardiovascular and risk factor evaluation of healthy American adults. A statement for physicians by an $A d H o c$ Committee appointed by the Steering Committee, American Heart Association. Circulation 75, 1340A-1362A.

Gurfinkel, E., Altman, R., Scazziota, A., Rouvier, J. \& Mautner, B. (1994). Importance of thrombosis and thrombolysis in silent ischaemia: comparison of patients with acute myocardial infarction and unstable angina. British Heart Journal 71, 151-155.

Heinrich, J., Balleisen, L., Schulte, H., Assmann, G. \& van de Loo, J. (1994). Fibrinogen and factor VII in the prediction of coronary risk. Results from the PROCAM study in healthy men. Arteriosclerosis \& Thrombosis 14, 54-59.

International Anticoagulant Review Group (1970). Collaborative analysis of long-term anticoagulant administration after acute myocardial infarction. Lancet i, 203-209.

Macfarlane, R. G. (1964). An enzyme cascade in the blood clotting mechanism, and its function as a biochemical amplifier. Nature 202, 498-499.

McNally, T., Mackie, I. J., Isenberg, D. A. \& Machin, S. J. (1996). $\beta_{2}$ glycoprotein-I inhibits factor XII activation on triglyceride rich lipoproteins: the effect of antibodies from plasma of patients with antiphospholipid syndrome. Thrombosis and Haemostasis 76, 220-225.

Marckmann, P., Sandström, B. \& Jespersen, J. (1993). Dietary effects on circadian fluctuation in human blood coagulation factor VII and fibrinolysis. Atherosclerosis 101, 225-234.

Miller, G. J., Martin, J. C., Mitropoulos, K. A., Esnouf, M. P., Cooper, J. A., Morrissey, J. H., Howarth, D. J. \& Tuddenham, E. G. D. (1996). Activation of factor VII during alimentary lipemia occurs in healthy adults and patients with congenital factor XII or factor XI deficiency, but not in patients with factor IX deficiency. Blood 87, 4187-4196.

Miller, G. J., Martin, J. C., Mitropoulos, K. A., Reeves, B. E. A., Thompson, R. L., Meade, T. W., Cooper, J. A. \& Cruickshank, J. K. (1991). Plasma factor VII is activated by postprandial triglyceridaemia, imespective of dietary fat composition. Atherosclerosis 86, 163-171.

Miller, G. J., Martin, J. C., Webster, J., Wilkes, H., Miller, N. E., Wilkinson, W. H. \& Meade, T. W. (1986). Association between dietary fat intake and plasma factor VII coagulant activity - a predictor of cardiovascular mortality. Atherosclerosis 60, 269-277.

Miller, G. J., Stirling, Y., Esnouf, M. P., Heinrich, J., van de Loo, J., Keinast, J., Wu, K. K., Morrissey, J. H., Meade, T. W., Martin, J. C., Imeson, J. D., Cooper, J. A. \& Finch A. (1994). Factor VII-deficient substrate plasmas depleted of protein $\mathrm{C}$ raise the sensitivity of the factor VII bio-assay to activated factor VII: an international study. Thrombosis and Haemostasis 71, 38-48.

Miller, G. J., Walter, S. J., Stirling, Y., Thompson, S. G. \& Esnouf, M. P. (1985). Assay of factor VII activity by two techniques: evidence for increased conversion of VII to $\alpha \mathrm{VII}_{\mathrm{a}}$ in hyperlipidaemia, with possible implications for ischaemic heart disease. British Joumal of Haematology 59, 249-258. 
Mitropoulos, K. A., Miller, G. J., Reeves, B. E. A., Wilkes, H. C. \& Cruickshank, J. K. (1989). Factor VII coagulant activity is strongly associated with the plasma concentration of large lipoprotein particles in middleaged men. Atherosclerosis 76, 203-208

Mitropoulos, K. A., Miller, G. J., Watts, G. F. \& Durrington, P. N. (1992). Lipolysis of triglyceride-rich lipoproteins activates coagulant factor XII: a study in familial lipoprotein-lipase deficiency. Atherosclerosis 95, 119-125.

Mitropoulos, K. A., Reeves, B. E. A. \& Miller, G. J. (1993). The activation of factor VII in citrated plasma by charged long-chain saturated fatty acids at the interface of large triglyceride-rich lipoproteins. Blood Coagulation and Fibrinolysis 4, 943-951

Morrissey, J. H., Macik, B. G., Neuenschwander, P. F. \& Comp, P. C. (1993). Quantitation of activated factor VII levels in plasma using a tissue factor mutant selectively deficient in promoting factor VII activation. Blood 81, 734-744.

Muller, J. E., Abela, G. S., Nesto, R. W. \& Tofler, G. H. (1994). Triggers, acute risk factors and vulnerable plaques: the lexicon of a new frontier. Journal of the American College of Cardiology 23, 809-813.

Ruddock, V. \& Meade, T. W. (1994). Factor VII activity and ischaemic heart disease: fatal and non-fatal events. Quarterly Joumal of Medicine 87, 403-406.

Salomaa, V., Rasi, V., Pekkanen, J., Jauhiainen, M., Vahtera, E., Pietinen, P., Korhonen, H., Kuulasmaa, K. \& Elnholm, C. (1993). The effects of saturated fat and $n-6$ polyunsaturated fat on postprandial lipemia and hemostatic activity. Atherosclerosis 103, 1-11.

Sanders, T. A. B., Miller, G. J., de Grassi, T. \& Yahia, N. (1996). Postprandial activation of coagulant factor VII by long-chain dietary fatty acids. Thrombosis and Haemostasis 76, 369-371.

Silveira, A., Karpe, F., Blomback, M., Steiner, G., Walldius, G. \& Hamsten, A. (1994). Activation of coagulation factor VII during alimentary lipemia. Arteriosclerosis \& Thrombosis 14, 60-69.

Simpson, H. R. C., Mann, J. I., Meade, T. W., Chakrabarti, R., Stirling, Y. \& Woolf, L. (1983). Hypertriglyceridaemia and hypercoagulability. Lancet i, 786-790.

Stirling, Y., Woolf, L., North, W. R. S., Seghatchian, M. J. \& Meade, T. W. (1984). Haemostasis in normal pregnancy. Thrombosis and Haemostasis 52, 176-182.

Wilcox, J. N., Smith, K. M., Schwartz, S. M. \& Gordon, D. (1989). Localization of tissue factor in the normal vessel wall and in the atherosclerotic plaque. Praceedings of the National Academy of Sciences, USA 86, 2839-2843.

Wildgoose, P., Nemerson, Y., Hansen, L. L., Nielsen, F. E., Glazer, S. \& Hedner, U. (1992). Measurement of basal levels of factor VIIa in hemophilia A and B patients. Blood 80, 25-28.

Yahia, N. \& Sanders, T. A. B. (1996). Influence of $n$-3 fatty acids on postprandial lipaemia and factor VII coagulant activity. Proceedings of the Nutrition Society 55, 173A. 